\title{
Seroprevalence and risk factors of Toxoplasma gondii infection in primary school children in Henan province, central China
}

\author{
Shuai Wang ${ }^{1, a}$, Zhijun Yao ${ }^{1, a}$, Haoran $\mathrm{Li}^{1, \mathrm{a}}$, Pengju $\mathrm{Li}^{1}$, Dong Wang ${ }^{1}$, Haizhu Zhang ${ }^{1}$, Qing Xie ${ }^{1}$, Zhenchao Zhang ${ }^{1, *}$ \\ and Xiangrui $\mathrm{Li}^{1,2, *}$ \\ ${ }^{1}$ Xinxiang Key Laboratory of Pathogenic Biology, School of Basic Medical Sciences, Xinxiang Medical University, Xinxiang, \\ 453003 Henan, PR China \\ ${ }^{2}$ MOE Joint International Research Laboratory of Animal Health and Food Safety, College of Veterinary Medicine, \\ Nanjing Agricultural University, Nanjing, 210095 Jiangsu, PR China
}

Received 20 December 2019, Accepted 21 March 2020, Published online 7 April 2020

\begin{abstract}
Toxoplasma gondii is an obligate intracellular protozoan parasite with global distribution. However, data on T. gondii infection among children in primary school in Henan province, central China were lacking. In this study, 2451 serum samples of primary school children in this province were collected from September 2015 to October 2018 and evaluated for $T$. gondii antibodies using an enzyme-linked immunosorbent assay (ELISA). The overall seroprevalence was $9.51 \%$ (233/2451), of which 7.59\% (186/2451) showed IgG positivity, $0.73 \%$ (18/2451) IgM and 1.18\% (29/2451) both. The main risk factors related to $T$. gondii infections were the age of children, residence area, contact with cats, and exposure to soil. Moreover, hand washing before eating was considered a protective factor. Seroprevalence of $T$. gondii infection among the study population was common, emphasizing the need to prevent and control this infection. This is the first report of $T$. gondii seroprevalence in primary school children in Henan province, central China.
\end{abstract}

Key words: Toxoplasma gondii, Primary school children, Seroprevalence, Risk factors, Central China.

Résumé - Séroprévalence et facteurs de risque de Toxoplasma gondii chez les enfants des écoles primaires de la province du Henan, en Chine centrale. Toxoplasma gondii est un parasite protozoaire intracellulaire obligatoire à distribution mondiale. Cependant, des informations concernant l'infection à $T$. gondii chez les enfants des écoles primaires n'étaient pas disponibles dans la province du Henan, en Chine centrale. Dans cette étude, 2451 échantillons de sérum d'élèves du primaire de cette province ont été collectés de septembre 2015 à octobre 2018 et évalués pour les anticorps contre T. gondii à l'aide d'un dosage immuno-enzymatique (ELISA). La séroprévalence globale était de 9,51\% (233/2451), dont 7,59\% (186/2451) représentaient la positivité des IgG, 0,73\% (18/2451) représentaient les $\operatorname{IgM}$ et $1,18 \%(29 / 2451)$ représentaient les deux. Les principaux facteurs de risque liés aux infections à $T$. gondii étaient l'âge des enfants, la zone de résidence des enfants, les contacts avec les chats et l'exposition au sol. De plus, le lavage des mains avant de manger est considéré comme un facteur protecteur. La séroprévalence contre $T$. gondii dans la population étudiée était courante, ce qui souligne la nécessité de prévenir et de contrôler cette infection. Il s'agit du premier signalement de la séroprévalence contre $T$. gondii chez les enfants des écoles primaires de la province du Henan.

\section{Introduction}

Toxoplasma gondii is a worldwide protozoan parasite that can infect virtually all warm-blooded animals, including humans. It has been estimated that one third of the world's population has been infected with $T$. gondii [24]. The main route for humans to become infected with $T$. gondii is ingestion of raw or undercooked meat containing $T$. gondii tissue cysts from intermediate hosts $[5,16,17]$. In addition, humans can be infected through consumption of food or water contaminated with sporulated T. gondii oocysts [22], and vertical transmission during pregnancy from an infected mother to her fetus [3]. Toxoplasma gondii infection in healthy individuals is usually asymptomatic or only shows self-limiting flu-like disease, but blindness and intellectual disability can be caused in congenitally infected children and serious complications in immunocompromized patients, such as AIDS, cancer, and transplant patients $[1,15,21]$. Children and young adults can also develop toxoplasmic chorioretinitis, which is a common manifestation of congenital or acute infection [20].

Although the seroprevalence of $T$. gondii infection in primary school children has been reported all over the

*Corresponding authors: zhangzhenchao525@163.com, lixiangrui@njau.edu.cn

${ }^{a}$ These authors contributed equally to this paper. 
Table 1. Prevalence of $T$. gondii infection in primary school children in the PR China.

\begin{tabular}{lcccccc}
\hline Provinces/Cities & Year of sampling & No. of tested & No. of positive & Prevalence (\%) & Method $^{\mathrm{a}}$ & Reference $^{\text {(\%) }}$ \\
\hline Nanchang, Jiangxi & 1991 & 632 & 32 & 5.06 & IHA, ELISA & [31] \\
Jiangmen, Guangdong & 1995 & 18,408 & 586 & 3.18 & ELISA & [26] \\
Boxing, Shandong & 2005 & 814 & 54 & 6.63 & IHA, ELISA & [18] \\
Qiqihar, Heilongjiang & 2006 & 357 & 19 & 5.32 & ELISA \\
Shiyan, Hubei & 2008 & 750 & 78 & 10.40 & [10] \\
Shandong & $2012-2014$ & 6000 & 961 & 16.02 & ELISA & [11] \\
\hline
\end{tabular}

${ }^{a}$ IHA: indirect hemagglutination test; ELISA: enzyme-linked immunosorbent assay.

world $[8,9,12]$, little is known about the seroprevalence of $T$. gondii infection in primary school children in China (Table 1; [10, 11, 18, 26, 29, 31]). Additionally, most of the articles reporting these data were published in local Chinese Journals in Chinese, and are not readily accessible to international readers. Moreover, reports on $T$. gondii seroprevalence among children in primary school in Henan province, central China are still lacking. Therefore, the objective of the present investigation was to examine $T$. gondii seroprevalence and relevant risk factors among primary school children in Henan province, central China.

\section{Materials and methods}

\section{Ethics statements}

In the current study, all of the protocols obtained the approval of the Ethics Committee of the Xinxiang Medical University (reference no. 2015018).

\section{The study area}

The region where we performed this study was Henan province, located in the central part of China, with a total area of $167,000 \mathrm{~km}^{2}$ and an approximate population of 106.01 million. The Yellow River flows through the middle section of Henan, which is seated located at north latitude $31^{\circ} 23^{\prime}-36^{\circ} 22^{\prime}$ and east longitude $110^{\circ} 21^{\prime}-116^{\circ} 39^{\prime}$. The area has a mainland monsoon-type climate, with mean annual precipitation and mean annual temperature of 532.5-1380.6 mm and $12.1-15.7^{\circ} \mathrm{C}$, respectively, and four distinctive seasons. Henan province has 17 cities and the capital is Zhengzhou.

\section{Sample collections}

In total, 2451 blood specimens were collected from primary school children aged from 6 years to 11 years participating in physical examinations and attending hospitals in four cities (Fig. 1) in Henan province from September 2015 to October 2018. Written informed consent was obtained from the parents/guardians of all included participants, after the objectives and procedures of this study were explained. A questionnaire was given to the parents/guardians of each child in order to gather information about risk factors, such as study region, sex, age, residential area, contact with cats, exposure to soil, and hand washing habits. Completed questionnaires were collected and stored for follow-up data analysis. All information collected was treated confidentially, and the data were coded and further analysed.

Blood samples were collected by well-trained nurses after obtaining assent from the participants and consent from their parents/guardians. Serum was separated by centrifuging blood samples and then transferred to $1.5 \mathrm{~mL}$ Eppendorf tubes for storage in a $-80^{\circ} \mathrm{C}$ freezer until testing for $T$. gondii antibodies.

\section{Antibodies to T. gondii}

Antibodies (IgG and IgM) to T. gondii were detected using commercially marketed ELISA kits purchased from Zhuhai S.E.Z. Haitai Biological Pharmaceuticals Co., Ltd., Zhuhai, China. The detection procedure followed the manufacturer's instructions. The sensitivity and specificity of IgG-ELISA were $92.9 \%$ and $97.3 \%$, respectively [14]. The sensitivity and specificity of IgM-ELISA were $93.55 \%$ and $100.0 \%$, respectively [28].

In brief, the test serum with a dilution ratio of 1:100 was added to each well in the coated plate and incubated at $37{ }^{\circ} \mathrm{C}$ for $30 \mathrm{~min}$. After additional washing with washing solution, $50 \mu \mathrm{L}$ peroxidase-conjugated anti-human immunoglobulin $\mathrm{G}$ (IgG) or $\operatorname{IgM}$ was added to the wells with incubation at $37{ }^{\circ} \mathrm{C}$ for $30 \mathrm{~min}$, followed by three washings with washing solution. Color reactions were developed by adding $50 \mu \mathrm{L}$ "A" solution and $50 \mu \mathrm{L}$ "B" solution at $37^{\circ} \mathrm{C}$ for $10 \mathrm{~min}$, and then the stopping solution was added to stop the reaction. Microplates were read at an optical density (OD) of $450 \mathrm{~nm}$ in the MK3 microplate reader (Thermo Fisher Scientific, Waltham, MA, USA) and ratios (OD $450 \mathrm{~nm}$ value of serum sample/OD $450 \mathrm{~nm}$ value of negative control) were calculated after correction for the OD $450 \mathrm{~nm}$ value of the blank. The test serum samples were considered positive when the ratio was $\geq 2.1$. The positive criterion for $\operatorname{IgG}$ and $\operatorname{IgM}$ was the same: a sample that was either IgG positive or IgM positive was considered a positive sample.

\section{Statistical analysis}

Statistical analysis was performed using SPSS 20 software for Windows (SPSS Inc., Chicago, IL, USA). Statistical analyses of $T$. gondii prevalence in different variables were performed by $\chi^{2}$-test. Results were considered statistically significantly different if the $p$-value was less than 0.05 . 


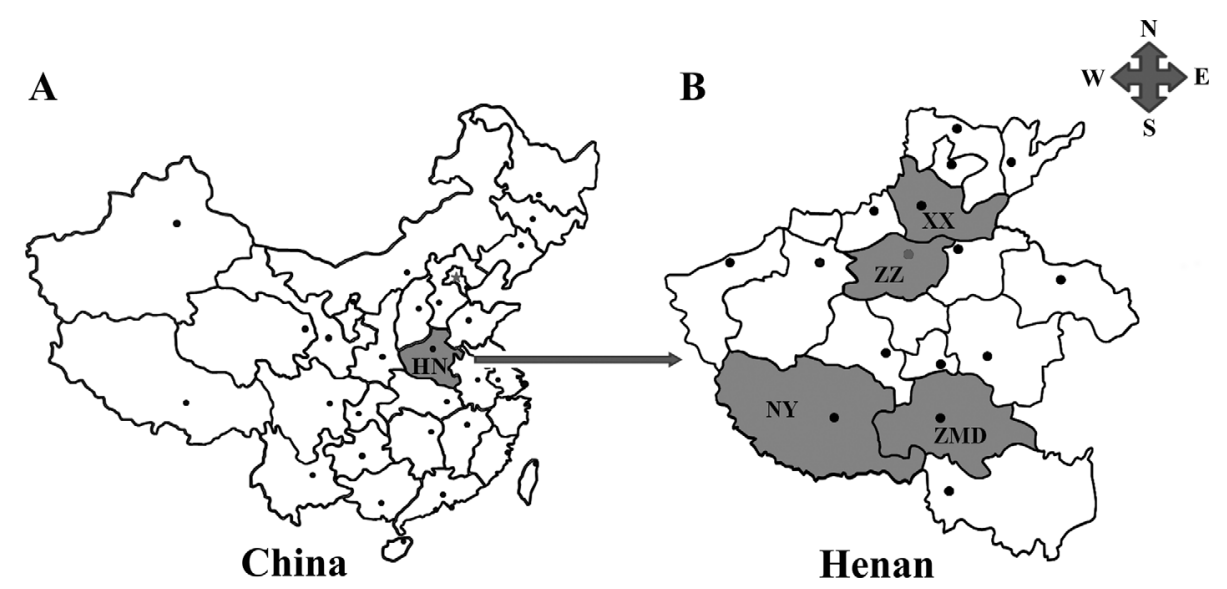

Figure 1. Geographic distribution of the sampling sites in Henan province, central China used in this study. (A) Henan province (HN, shadowed areas) is located in the central part of mainland China. (B) Shadowed areas are the sampling locations for the present survey. XX: Xinxiang; ZZ: Zhengzhou; NY: Nanyang; ZMD: Zhumadian.

\section{Results}

As shown in Table 2, the overall seroprevalence of T. gondii among primary school children in Henan province was $9.51 \% ; 7.59 \%$ (95\% CI [6.54-8.64]) of children were positive for anti-T. gondii $\mathrm{IgG}$ antibodies only, $0.73 \%(95 \% \mathrm{CI}$ [0.40-1.07]) of children were positive for anti-T. gondii IgM antibodies only, and $1.18 \%$ (95\% CI [0.76-1.61]) of children were positive for both anti-T. gondii $\operatorname{IgG}$ and IgM antibodies.

According to Table 3, T. gondii seroprevalence among the children living in Xinxiang, Zhengzhou, Zhumadian, and Nanyang was $10.60 \%, 7.04 \%, 12.12 \%$, and $8.53 \%$, respectively. The prevalence of $T$. gondii antibodies varied significantly with the place of residence $(p<0.05)$. There was no significant difference in the seroprevalence of $T$. gondii between boys $(9.78 \%, 95 \% \mathrm{CI}[8.15-11.40])$ and girls $(9.21 \%, 95 \% \mathrm{CI}$ [7.55-10.87]) $\left(\chi^{2}=0.228, p=0.633\right)$.

The overall $T$. gondii seroprevalence increased with increasing age (Table 3). In comparison to groups of 6-7-year-olds (7.57\%) and 8-9-year-olds (9.44\%), the T. gondii seroprevalence among older primary school children (10-11-year-olds) (11.44\%, 95\% CI [9.30-13.58]) was higher.

The seropositive rate of $T$. gondii in children living in rural areas was significantly higher than that in urban areas ( $p<0.001)$. The seroprevalence of $T$. gondii in primary school children who had contact with cats was $12.23 \%$, while $7.66 \%$ of primary school children who had no contact with cats were seropositive for $T$. gondii. Similarly, the probability that children became infected by $T$. gondii was increased by touching soil in comparison to no touching $(10.99 \%$ vs. $5.46 \%$, $\left.\chi^{2}=17.131, p<0.001\right)$. Children with the behavior of washing hands before eating had lower seropositive rates for $T$. gondii than those without (7.32 vs. $\left.14.16, \chi^{2}=28.996, p<0.001\right)$.

\section{Discussion}

Toxoplasma gondii infection in humans is widespread all around the world, and the prevalence varies in accordance with age, dietary habits, and environment $[13,30]$. It was reported
Table 2. Seroprevalence of anti-T. gondii IgG and IgM antibodies in 2451 primary school children in Henan province, central China.

\begin{tabular}{lccc}
\hline Antibodies & $\begin{array}{c}\text { Absolute } \\
\text { frequency }\end{array}$ & $\begin{array}{c}\text { Relative } \\
\text { frequency (\%) }\end{array}$ & $95 \%$ CI \\
\hline $\mathrm{IgG}^{+}, \mathrm{IgM}^{-}$ & 186 & 7.59 & $6.54-8.64$ \\
$\mathrm{IgG}^{-}, \mathrm{IgM}^{+}$ & 18 & 0.73 & $0.40-1.07$ \\
$\mathrm{IgG}^{+}, \mathrm{IgM}^{+}$ & 29 & 1.18 & $0.76-1.61$ \\
$\mathrm{IgG}^{-}, \mathrm{IgM}^{-}$ & 2218 & 90.49 & $89.33-91.65$ \\
Total & 2451 & 100.00 & \\
\hline
\end{tabular}

+: positive; -: negative; CI: confidence interval.

that the $T$. gondii prevalence in the Chinese population was about $7 \%$ during the two nation-wide surveys conducted in 1995 and 2004 [6], and increased up to $12.3 \%$ in 2010 [27].

It was revealed by this study that the total $T$. gondii seropositive rate was $9.51 \%$ in primary school children in Henan province, which was lower than the values of $16.02 \%$ among primary school children in Shandong province, eastern China [29], $14.4 \%$ in western Romania [4], 54.8\% in the Republic of the Marshall Islands [9], and $63.1 \%$ in the Democratic Republic of São Tomé and Príncipe, West Africa [8]. The total T. gondii seropositive rate in Henan province was similar to the infection rate in Tehran, Iran (9.9\%) [2] and Shiyan, China (10.4\%) [11], but higher than that observed in Nanchang (5.06\%) [31], Jiangmen (3.18\%) [26], Boxing (6.63\%) [18], and Qiqihar (5.32\%) [10] in China. It is possible that various lifestyles, dietary habits, and geographical conditions are the most important factors underlying these differences, in addition to different investigational methods used.

In this study, male or female sex was not correlated with T. gondii seroprevalence, which was consistent with other reports [8, 9, 29].

It was indicated by previous studies that $T$. gondii seroprevalence was positively correlated with age of children $[12,23$, 29], which also aligned with the results of the current study. It was hypothesized that this may result from increased exposure years as the child grows [12, 29]. 
Table 3. T. gondii infection in primary school children in Henan province, central China.

\begin{tabular}{|c|c|c|c|c|c|c|}
\hline Variable & No. of tested & No. of positive & Prevalence (\%) & $95 \% \mathrm{CI}$ & $\chi^{2}$ & $p$-value \\
\hline \multicolumn{7}{|l|}{ Region } \\
\hline Xinxiang & 585 & 62 & 10.60 & 8.10-13.09 & \multirow[t]{4}{*}{11.243} & \multirow[t]{4}{*}{0.010} \\
\hline Zhengzhou & 696 & 49 & 7.04 & $5.14-8.94$ & & \\
\hline Zhumadian & 619 & 75 & 12.12 & $9.55-14.69$ & & \\
\hline Nanyang & 551 & 47 & 8.53 & $6.20-10.86$ & & \\
\hline \multicolumn{7}{|l|}{ Sex } \\
\hline Male & 1289 & 126 & 9.78 & $8.15-11.40$ & \multirow[t]{2}{*}{0.228} & \multirow{2}{*}{0.633} \\
\hline Female & 1162 & 107 & 9.21 & $7.55-10.87$ & & \\
\hline \multicolumn{7}{|l|}{ Age (years) } \\
\hline $6-7$ & 819 & 62 & 7.57 & $5.76-9.38$ & \multirow[t]{3}{*}{7.254} & \multirow[t]{3}{*}{0.027} \\
\hline $8-9$ & 784 & 74 & 9.44 & $7.39-11.49$ & & \\
\hline $10-11$ & 848 & 97 & 11.44 & $9.30-13.58$ & & \\
\hline \multicolumn{7}{|l|}{ Residence area } \\
\hline Urban & 1127 & 71 & 6.30 & $4.88-7.72$ & \multirow{2}{*}{24.934} & \multirow[t]{2}{*}{$<0.001$} \\
\hline Rural & 1324 & 162 & 12.24 & $10.47-14.00$ & & \\
\hline \multicolumn{7}{|c|}{ Contact with cats } \\
\hline No & 1462 & 112 & 7.66 & $6.30-9.02$ & \multirow[t]{2}{*}{14.346} & \multirow[t]{2}{*}{$<0.001$} \\
\hline Yes & 989 & 121 & 12.23 & $10.19-14.28$ & & \\
\hline \multicolumn{7}{|c|}{ Exposure to soil } \\
\hline No & 659 & 36 & 5.46 & $3.73-7.20$ & \multirow[t]{2}{*}{17.131} & \multirow[t]{2}{*}{$<0.001$} \\
\hline Yes & 1792 & 197 & 10.99 & $9.55-12.44$ & & \\
\hline \multicolumn{7}{|c|}{ Hand washing before eating } \\
\hline No & 784 & 111 & 14.16 & $11.72-16.60$ & \multirow[t]{3}{*}{28.996} & \multirow[t]{3}{*}{$<0.001$} \\
\hline Yes & 1667 & 122 & 7.32 & $6.07-8.57$ & & \\
\hline Total & 2451 & 233 & 9.51 & $8.35-10.67$ & & \\
\hline
\end{tabular}

Felids act as the only final host of $T$. gondii and thus play an essential role in transmitting this parasite. Infected cats are considered to be a potential threat to public health because they can excrete environmentally resistant oocysts in their feces [25]. In mainland China, seroprevalence of $T$. gondii infection in cats ranged from $3.9 \%$ to $79.4 \%$ [7]. The seropositive rate of $T$. gondii infection in domestic cats was $21.84 \%$ in Henan province [25]. Domestic cats are important companion animals of humans. In this study, contact with cats and touching soil have been found to be risk factors for children to exhibit $T$. gondii antibody positivity, consistent with the results of other studies $[19,23]$. In the future, more research is needed to evaluate the prevalence of $T$. gondii oocysts in the soil of local parks and primary schools.

The seropositive rate of $T$. gondii in children living in rural areas was significantly higher than that in urban areas, which was consistent with other reports $[4,19]$. Our previous research results confirmed that the seroprevalence of $T$. gondii in rural cats $(29.26 \%)$ was significantly higher than in urban cats (16.35\%) in Henan province [25]. This may lead to increased environmental contamination by $T$. gondii oocysts in rural areas, which in turn increases the risk of exposure to $T$. gondii in children. Additionally, hand washing before eating has been verified as a protective factor related to $T$. gondii seroprevalence in this study. This finding is in accordance with other similar surveys $[19,23]$.

\section{Conclusion}

In conclusion, the results of this study suggest that $T$. gondii infection in primary school children is common in Henan province, central China. It is possibly helpful and necessary to take preventive actions like preventing soil from being contaminated by feces of infected cats, and educating children to wash hands before eating in this area.

\section{Conflict of interest statement}

We declare that we have no conflict of interest.

Acknowledgements. The current study received support from the National Natural Science Foundation of China (No. 81702025), the Science and Technology Planning Project of Henan Province (Nos. 182102310220 and 182102310431) and the Doctoral Scientific Research Activation Foundation of Xinxiang Medical University (Nos. XYBSKYZZ201504 and XYBSKYZZ201631).

\section{References}

1. Abbasi Fard S, Khajeh A, Khosravi A, Mirshekar A, Masoumi S, Tabasi F, Hassanzadeh T, Mortazavi MM. 2020. Fulminant and diffuse cerebral toxoplasmosis as the first manifestation of HIV infection: a case presentation and review of the literature. American Journal of Case Reports, 21, e919624.

2. Ali Z, Hossein MM, Khadijeh D. 2007. Toxoplasma chorioretinitis in primary school children in Tehran, Iran, 2003-2004. Medical Science Monitor, 13(4), CR201-CR205.

3. Arora N, Sadovsky Y, Dermody TS, Coyne CB. 2017. Microbial vertical transmission during human pregnancy. Cell Host \& Microbe, 21(5), 561-567.

4. Capraru ID, Lupu MA, Horhat F, Olariu TR. 2019. Toxoplasmosis seroprevalence in Romanian Children. Vector Borne Zoonotic Diseases, 19(11), 867-869. 
5. Colosimo SM, Montoya JG, Westley BP, Jacob J, Isada NB. 2013. Congenital toxoplasmosis presenting with fetal atrial flutter after maternal ingestion of infected moose meat. Alaska Medicine, 54, 27-31.

6. Coordinating Office of the National Survey on the Important Human Parasitic D. 2005. A national survey on current status of the important parasitic diseases in human population. Chinese Journal of Parasitology \& Parasitic Diseases, 23(5 Suppl), 332-340. (in Chinese).

7. Ding H, Gao YM, Deng Y, Lamberton PH, Lu DB. 2017. A systematic review and meta-analysis of the seroprevalence of Toxoplasma gondii in cats in mainland China. Parasites \& Vectors, 10(1), 27

8. Fan CK, Lee LW, Liao CW, Huang YC, Lee YL, Chang YT, da Costa Ados S, Gil V, Chi LH, Nara T, Tsubouchi A, Akinwale OP. 2012. Toxoplasma gondii infection: relationship between seroprevalence and risk factors among primary schoolchildren in the capital areas of Democratic Republic of Sao Tome and Principe, West Africa. Parasites \& Vectors, 5, 141.

9. Fu CJ, Chuang TW, Lin HS, Wu CH, Liu YC, Langinlur MK, Lu MY, Hsiao WW, Fan CK. 2014. Toxoplasma gondii infection: seroprevalence and associated risk factors among primary school children in the capital area of the Republic of the Marshall Islands. Japanese Journal of Infectious Diseases, 67(5), 405-410.

10. Guo JJ, Jiang YC, Ma Q. 2006. Prevalence of ascariasis and toxoplasmosis in children in Tsitsihar. Journal of Qiqihar Medical University, 27(17), 2104-2105. (in Chinese).

11. Guo EP, Li JT, Zhang GY, Wang SJ, Song MH. 2008. Prevalence of Toxoplasma gondii infection among pupils in Shiyan. Chinese Journal of School Health, 29(4), 345-346. (in Chinese).

12. Gyang VP, Akinwale OP, Lee YL, Chuang TW, Orok A, Ajibaye O, Liao CW, Cheng PC, Chou CM, Huang YC, Fan KH, Fan CK. 2015. Toxoplasma gondii infection: seroprevalence and associated risk factors among primary schoolchildren in Lagos City, Southern Nigeria. Revista da Sociedade Brasileira de Medicina Tropical, 48(1), 56-63.

13. Hosseini SA, Amouei A, Sharif M, Sarvi S, Galal L, Javidnia J, Pagheh AS, Gholami S, Mizani A, Daryani A. 2019. Human toxoplasmosis: a systematic review for genetic diversity of Toxoplasma gondii in clinical samples. Epidemiology \& Infection, 147, e36.

14. Jihui D, Shifeng Z. 2003. Comparison of domestic and imported enzyme-linked immunoassay kits for detection of anti-Toxoplasma gondii IgG antibody. Chinese Journal of Zoonoses, 19 (05), 127. (in Chinese).

15. Khan K, Khan W. 2018. Congenital toxoplasmosis: an overview of the neurological and ocular manifestations. Parasitology International, 67(6), 715-721.

16. Kim CS, Kim DS, Jung HR. 2019. Toxoplasma lymphadenitis caused by ingestion of raw blood and meat of deer in a 10 -yearold boy. Pediatrics \& Neonatology, 60(1), 112-113.

17. Lambooij MS, Veldwijk J, van Gils P, Mangen MJ, Over E, Suijkerbuijk A, Polder J, de Wit GA, Opsteegh M. 2019. Consumers' preferences for freezing of meat to prevent toxoplasmosis - a stated preference approach. Meat Science, 149, 1-8.
18. Li GQ, Du TY, Wang ZQ. 2005. Investigation on Toxoplasma gondii infection among disabled pupils in Boxing County. Chinese Journal of Parasitic Disease Control, 18(5), 335. (in Chinese).

19. Meng QF, You HL, Zhou N, Dong W, Wang WL, Wang WL, Cong W. 2015. Seroprevalence of Toxoplasma gondii antibodies and associated risk factors among children in Shandong and Jilin provinces, China. International Journal of Infectious Diseases, 30, 33-35.

20. Montoya JG, Remington JS. 1996. Toxoplasmic chorioretinitis in the setting of acute acquired toxoplasmosis. Clinical Infectious Diseases, 23(2), 277-282.

21. Papazoglou A, Zweifel S, Barthelmes D, Al-Sheikh M, Boeni C. 2018. Toxoplasma gondii-associated bilateral panuveitis and encephalitis after bone marrow transplantation. Klin Monatsbl Augenheilkd, 235(4), 478-479.

22. Pinto-Ferreira F, Caldart ET, Pasquali AKS, Mitsuka-Bregano R, Freire RL, Navarro IT. 2019. Patterns of transmission and sources of infection in outbreaks of human toxoplasmosis. Emerging Infectious Diseases, 25(12), 2177-2182.

23. Sharif M, Daryani A, Barzegar G, Nasrolahei M. 2010. A seroepidemiological survey for toxoplasmosis among schoolchildren of Sari, Northern Iran. Tropical Biomedicine, 27(2), 220-225.

24. Wang S, Lan C, Zhang L, Zhang H, Yao Z, Wang D, Ma J, Deng J, Liu S. 2015. Seroprevalence of Toxoplasma gondii infection among patients with hand, foot and mouth disease in Henan, China: a hospital-based study. Infectious Diseases of Poverty, 4, 53.

25. Wang S, Zhou Y, Niu J, Xie Q, Xiao T, Chen Y, Li H, Ma C, Zhang H, Liu S, Zhang Z. 2017. Seroprevalence of Toxoplasma gondii infection in domestic cats in central China. Parasite, 24, 10.

26. $\mathrm{Wu}$ AL, Zhou CH. 1999. Serological investigation of Toxoplasma gondii infection among primary and middle school students in Jiangmen City. Chinese Journal of School Health, 20(2), 135-136. (in Chinese).

27. Xiao Y, Yin J, Jiang N, Xiang M, Hao L, Lu H, Sang H, Liu X, Xu H, Ankarklev J, Lindh J, Chen Q. 2010. Seroepidemiology of human Toxoplasma gondii infection in China. BMC Infect Dis, 10, 4.

28. Xiaodong S, Xuezhong W, Su Y, Yingyi Y, Yan L, Hui L, Jian W, Huaixian W, Zaixing Z. 2008. Evaluation of a commercial ELISA kit for detection of IgM antibodies to Toxoplasma gondii. Chinese Journal of Zoonoses, 24(10), 978-981. (in Chinese).

29. Xin KS, Liu H, Wang HB, Yao ZL. 2015. Seroprevalence of Toxoplasma gondii among primary school children in Shandong Province, China. The Korean Journal of Parasitology, 53(4), 489-492.

30. Yan C, Liang LJ, Zheng KY, Zhu XQ. 2016. Impact of environmental factors on the emergence, transmission and distribution of Toxoplasma gondii. Parasites \& Vectors, 9, 137.

31. Yao YY, Kang P, Yi GL, Shen SY, Qu ZY, Xiao D, Xiao JH, Ding ZY. 1991. Investigation on Toxoplasma gondii infection among pupils in Nanchang City. Chinese Journal of School Health, 12(4), 230. (in Chinese).

Cite this article as: Wang $\mathrm{S}$, Yao Z, Li H, Li P, Wang D, Zhang H, Xie Q, Zhang Z \& Li X. 2020. Seroprevalence and risk factors of Toxoplasma gondii infection in primary school children in Henan province, central China. Parasite 27, 23. 
S. Wang et al.: Parasite 2020, 27, 23

An international open-access, peer-reviewed, online journal publishing high quality papers on all aspects of human and animal parasitology

Reviews, articles and short notes may be submitted. Fields include, but are not limited to: general, medical and veterinary parasitology; morphology, including ultrastructure; parasite systematics, including entomology, acarology, helminthology and protistology, and molecular analyses; molecular biology and biochemistry; immunology of parasitic diseases; host-parasite relationships; ecology and life history of parasites; epidemiology; therapeutics; new diagnostic tools.

All papers in Parasite are published in English. Manuscripts should have a broad interest and must not have been published or submitted elsewhere. No limit is imposed on the length of manuscripts.

Parasite (open-access) continues Parasite (print and online editions, 1994-2012) and Annales de Parasitologie Humaine et Comparée (1923-1993) and is the official journal of the Société Française de Parasitologie. 